\title{
Morphometric Analysis of Vertebral Artery Groove in Human Atlas Vertebra in South Indian Population
}

\section{Suganya Saminathan.}

Assistant Professor of Anatomy, PSGIMS \& R, Coimbatore, Tamilnadu, India.

\section{ABSTRACT}

\begin{abstract}
Introduction: Recent trends like pedicle screws and other instrumentation of cervical vertebra are on the rise. However, proximity of vertebral artery coursing in vertebral artery groove (VAG) on the superior surface of the posterior arch of atlas poses a unique challenge to surgeons performing these procedures. Such vascular injuries though rare, are not uncommon and may pose immediate to delayed complications. Radiological studies of atlas vertebra \& VAG are being extensively done with CT and MR Angiography, but morphometric studies of VAG in atlas vertebra in South Indian population is lacking.
\end{abstract}

Aims: To understand the morphology and dimensions of the vertebral artery groove and its variations if any, in dry atlas vertebra of South Indian population.

Settings and Design: Descriptive observational study

Methods and Material: 50 dried adult human atlas vertebra of unknown age \& sex from the Anatomy Department, PSGIMS \& R, Coimbatorewere studied. Intact cervical vertebrae without any degenerative or traumatic disorders were included. The morphometry of VAG and its distance from midline were evaluated through six linear measurements.The parameters were inner and outer lengths of the groove, width \& thickness of the groove and the distance of its medial most and lateral most edges from the midline on both sides.

Statistical analysis used: SPSS software

Results: There is no statistically significant difference between mean values on right and left side for inner length, outer length, width and thickness of vertebral artery groove. The mean inner and outer distance of the vertebral artery groove from the midline on the right is higher than the left.

Conclusions: The present study provides morphometric data of VAG \& recommends a safe zone of $11.82 \mathrm{~mm}$ from midline for instrumentation in posterior spinal surgeries to minimize vertebral artery injuries.

KEY WORDS: Atlas, Morphometry, Screw Fixation, Vascular Injury, Vertebral Artery.

Corresponding Author: Dr. Suganya Saminathan, Assistant Professor of Anatomy, PSGIMS \& R, Coimbatore, Tamilnadu, India - 641004. E-Mail: suganss02@gmail.com

Access this Article online

\section{Quick Response code}

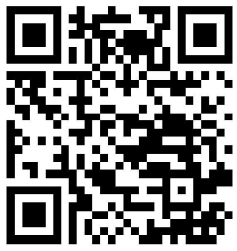

DOI: $10.16965 /$ ijar.2021.194

Journal Information

International Journal of Anatomy and Research

ISSN (E) 2321-4287 | ISSN (P) 2321-8967

https://www.ijmhr.org/ijar.htm

DOI-Prefix: https://dx.doi.org/10.16965/ijar

Article Information

Received: 01 Dec 2021

Peer Review: 02 Dec 2021

Revised: 04 Jan 2022
Accepted: 02 Feb 2022

Published (O): 05 Mar 2022

Published (P): 05 Mar 2022

\section{INTRODUCTION}

The first cervical vertebra, Atlas, is an atypical vertebra owing to its unique shape and absence of body. On the superior surface of the posterior arch of atlas is the groove for the lodgement of the third part of vertebral artery, also known as V3 segment of vertebral artery (VA) [1]. This segment of VA is prone for injury during posterior spinal procedures like drilling, tapping \& screw fixation [2].

Such injuries though rare, are not uncommon. They might result in immediate to late onset complications like arteriovenous fistulae, pseudo aneurysm, thrombo embolic incidents, cerebral and cerebellar ischaemia, stroke and even death [3-9]. Highest reported cases of VA injuries are associated with posterior $\mathrm{C} 1-\mathrm{C} 2$ 
trans articular fixation for atlanto axial instability at $0 \%$ to $8.2 \%$ [10-12]. According to Lunardini, VA injuries in posterior spinal approaches amounted to $11.7 \%$ of all VA injuries; $32.4 \%$ of instrumentation associated VA injuries were caused by posterior upper cervical instrumentation [13]. Eskander has documented that in magnetic resonance angiography of cervical spinal region, $7.6 \%$ of images showed midline migration of the vertebral artery [14].

To prevent such vascular injuries it is imperative to determine the safe trajectory for screw placements with regard to the atlas vertebral morphometric dimensions in general and that of vertebral artery groove (VAG) in specific with a constant attention to the intraoperative identification of the anatomic landmarks for safe dissection and instrumentation. Hence a thorough knowledge of the quantitative anatomy of VAG is therefore necessary.

The morphometric data regarding the vertebral artery groove of the atlas vertebra of South Indian population is minimal. So this study aims at achieving such data in providing the length, width, thickness of the bone forming the groove's floor and the distance of the medial and lateral edges of the groove from the midline and comparing it with previous studies of same $\&$ different ethnic groups.

\section{MATERIALS AND METHODS}

This is a descriptive observational study aiming to study the morphometry of the vertebral artery groove bilaterally on the superior surface of the posterior arch of 50 dried adult human atlas vertebra of unknown age \& sex from the Department of Anatomy, PSG Institute of Medical Sciences \& Research, Coimbatore using digital Vernier caliper accurate to $0.01 \mathrm{~mm}$ for linear measurements. Intact cervical vertebrae without any degenerative or traumatic disorders were included in this study.

The morphometry of VAG and its distance from midline were evaluated through six linear measurements. The parameters which were measured were the inner and outer lengths of the groove, width of the groove, thickness of the bone forming the floor of the groove and the distance of its medial most and lateral most edges of the groove from the midline. All the variables were studies on both right and left sides.

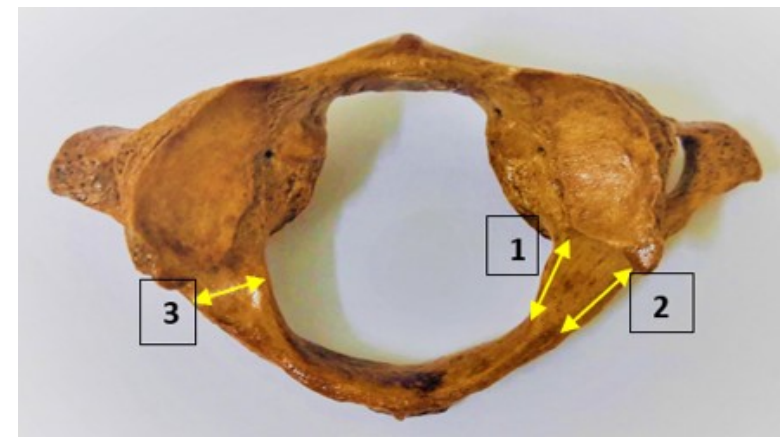

Fig. 1: Showing the measurements of 1 . Inner length of the vertebral artery groove 2. Outer Length of the vertebral groove, 3 . Width of the groove.

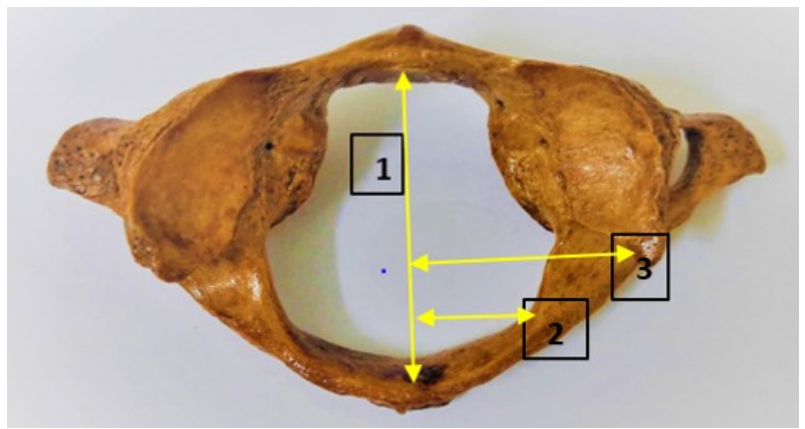

Fig. 2: Showing the Measurement of 1 . Midline, 2. Distance between the medial most edge of the groove $\&$ midline, 3. Distance between the lateral most edge of the groove \& midline.

All the parameters were measured according to the guidelines of Max Franco et al, Ravichandran et al \& Gupta et al [15-17] at the appropriate places [Table/Fig-1 \& 2].

The inner length of the groove was taken as the maximum anteroposterior distance along the inner edge of the groove.

The outer length of the groove was taken as the maximum anteroposterior distance along the outer edge of the groove.

The width of the groove is the distance between the inner and outer edges at the middle of the groove.

The thickness of the bone which formed the floor of the groove is the distance between the superior and inferior surfaces of the posterior arch at the middle of the groove. [Fig 3]

Inner distance of vertebral artery groove was measured as the distance from midline to the medial-most edge of the vertebral artery groove on inner cortex. 


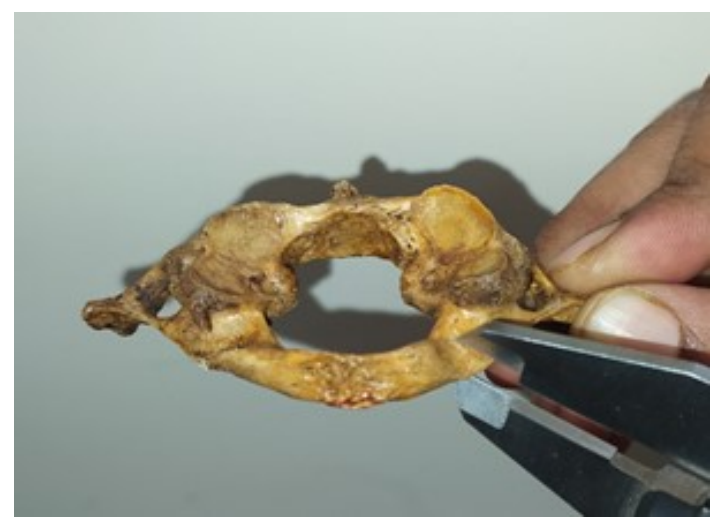

Fig. 3: Measuring the thickness of Vertebral artery groove.

Outer distance of vertebral artery groove was measured as the distance from midline to the lateral-most edge of the vertebral artery groove on outer cortex.

All the parameters were measured at the appropriate places. The length of the groove was taken as the maximum antero posterior distance along the inner and outer edges of the vertebral artery groove. The width of the vertebral artery groove is the distance between the inner and outer edges of the groove along its middle (Fig 1). The thickness of the groove is obtained by measuring the distance between the superior and inferior surfaces of the groove along its middle (Fig3). The distance between the midline axis and the medial most and lateral most edges of the groove are also measured (Fig 2).

The mean value of each of the above described parameters were calculated. Statistical analysis was done using the SPSS version 16 package.

\section{RESULTS}

The mean inner length of the vertebral artery groove on the atlas vertebra on the right side was $7.69 \pm 1.13$ and on the left side was $7.52 \pm 1.24$. The mean outer length of the vertebral artery groove on the right side was $8.21 \pm 1.24$ and on the left side was $8.27 \pm 1.32$. The mean width of the vertebral artery groove on the right side was $7.78 \pm 1.21$ and on the left side was $8.12 \pm 1.44$. The mean thickness of the floor of the vertebral artery groove on the right side was $4.76 \pm 0.91$ and on the left side was $4.62 \pm 1.04$. The mean distance between the medial most edge of the vertebral artery groove from the midline(Inner distance of vertebral artery groove) on the right side was $12.89 \pm 1.06$ and on the left side was $10.74 \pm 1.12$. The mean distance of the lateral most edge of the vertebral artery groove from the midline (Outer distance of vertebral artery groove) on the right side was $23.86 \pm 1.11$ and on the left side was $20.19 \pm 1.24$. (Table 1 )

There is no statistically significant difference between mean values on right and left sides for inner length, outer length, width and thickness of vertebral artery groove. The mean inner and outer distances of the vertebral artery groove on the right side is higher than the left side. The results are statistically significant.

Table 1: Comparison of mean values between right and left sides.

\begin{tabular}{|c|c|c|c|c|c|c|c|}
\hline \multirow{2}{*}{ Parameter } & \multicolumn{2}{|c|}{ Right } & \multicolumn{2}{|c|}{ Left } & \multirow{2}{*}{$\begin{array}{c}\text { Mean } \\
\text { difference }\end{array}$} & \multirow{2}{*}{ T value } & \multirow{2}{*}{$P$ value } \\
\hline & Mean & SD & Mean & SD & & & \\
\hline Inner length of the groove & 7.69 & 1.13 & 7.52 & 1.24 & 0.17 & 0.707 & 0.475 \\
\hline Outer length of the groove & 8.21 & 1.24 & 8.27 & 1.32 & 0.06 & -0.234 & 0.815 \\
\hline Width of the groove & 7.78 & 1.21 & 8.12 & 1.44 & 0.34 & -1.278 & 0.204 \\
\hline Thickness of the groove's floor & 4.76 & 0.91 & 4.62 & 1.04 & 0.14 & 0.716 & 0.475 \\
\hline $\begin{array}{l}\text { Inner distance of vertebral artery } \\
\text { groove from midline }\end{array}$ & 12.89 & 1.06 & 10.74 & 1.12 & 2.15 & 9.859 & $<0.001$ \\
\hline $\begin{array}{l}\text { Outer distance of vertebral artery } \\
\text { groove from midline }\end{array}$ & 23.86 & 1.11 & 20.19 & 1.24 & 3.67 & 15.593 & $<0.001$ \\
\hline
\end{tabular}

\section{DISCUSSION}

Surgical procedures and instrumentation of cranio-cervical junction has increased in recent days. This is associated with a relative increase in intra operative vascular complications too.
Hence more information about the bones and adjacent anatomy is necessary. The measurements done in this study may be helpful in avoiding and reducing vascular injuries to VA . Max franco et al [15] found the mean inner 
length of VAG as $7.58 \mathrm{~mm}$ and $7.29 \mathrm{~mm}$ and the mean outer length of VAG as $9.68 \mathrm{~mm}$ and $9.54 \mathrm{~mm}$ on right and left sides respectively among the Brazilian population. He also documented the mean width of VAG as $8.49 \mathrm{~mm}$ and $7.96 \mathrm{~mm}$ on the right and left sides respectively.

Ravichandran et al [16], in a similar study among south Indian population found the mean inner length of VAG to be $7.71 \mathrm{~mm}$ and $7.49 \mathrm{~mm}$; the mean outer length of VAG were $8.10 \mathrm{~mm}$ and $8.24 \mathrm{~mm}$ right and left sides respectively. In his study the mean width of VAG were $7.89 \mathrm{~mm}$ and $8.08 \mathrm{~mm}$ on the right and left sides respectively.

In present study, the mean inner length of VAG were $7.69 \mathrm{~mm}$ and $7.52 \mathrm{~mm}$; the mean outer length of VAG were $8.21 \mathrm{~mm}$ and $8.27 \mathrm{~mm}$ on the right and left sides respectively. The mean width of the VAG were $7.78 \mathrm{~mm}$ and $8.12 \mathrm{~mm}$ on the right and left sides respectively. Based on these parameters the results of the present study done in South Indian population were found to be similar to that of studies done in Brazilian population by Max franco et $\mathrm{al}^{15}$ and in South Indian population done by Ravichandran et al [16].

The mean thickness of VAG were found to be $4.76 \mathrm{~mm}$ and $4.62 \mathrm{~mm}$ on the right and left sides respectively in the present study $\& 3.87 \mathrm{~mm}$ and $3.92 \mathrm{~mm}$ in Max Franco et al's [15] study \& $4.48 \mathrm{~mm}$ and $4.49 \mathrm{~mm}$ in Akram et al's [18] studyon the right and left sides respectively.
Ravichandran et al [16] observed the mean thickness of VAG as $4.7 \mathrm{~mm}$ and $4.55 \mathrm{~mm}$ on the right and left sides respectively. The results of the present study are similar to that of Akram et al's [19] study done in Egyptian population and Ravichandran et al's study [16] done in South Indian population.

The inner distance of the VAG from the midline were $12.89 \mathrm{~mm}$ and $10.74 \mathrm{~mm}$ on the right and left sides respectively in the present study. These values were found to be $14.26 \mathrm{~mm}$ and $14.30 \mathrm{~mm}$ in Ravichandran et al study [16]; $12.8 \mathrm{~mm}$ and $13.8 \mathrm{~mm}$ in Gupta et al 's study [17]; $10.73 \mathrm{~mm}$ and $9.72 \mathrm{~mm}$ in Mukesh et al's study [19] on the right and left sides respectively. The outer distance of the VAG from the midline were found to be $23.86 \mathrm{~mm}$ and $20.19 \mathrm{~mm}$ on the right and left sides respectively in the present study. These were found to be $17.04 \mathrm{~mm}$ and $17.82 \mathrm{~mm}$ in Ravichandran et al's study [16]; $23.0 \mathrm{~mm}$ and $22.0 \mathrm{~mm}$ in Gupta et al's study [17]; $20.4 \mathrm{~mm}$ and $18.86 \mathrm{~mm}$ in Mukesh et al's study [19] on the right and left sides respectively. The studies compared with respect to these two parameters were all done in Indian population. It is found that the inner distance of VAG from the midline has differences in all the compared studies, whereas the outer distance of the VAG from the midline was found to be similar in the present study and that by Gupta et al [17][Table 2.]

Table 2: Comparison of the results of present study with others.

\begin{tabular}{|c|c|c|c|c|c|}
\hline Author & Mean Length ( \pm SD) & Mean Width ( \pm SD) & Mean Thickness $( \pm$ SD) & $\begin{array}{l}\text { Inner distance of VAG } \\
\text { from the midline ( }+ \text { S.D) }\end{array}$ & $\begin{array}{l}\text { Outer distance of VAG } \\
\text { from the midline ( } \pm \text { S.D) }\end{array}$ \\
\hline $\begin{array}{l}\text { Max Franco } \\
{[15][\text { Brazil,2007] }}\end{array}$ & $\begin{array}{l}\text { INNER: Right : } 7.58 \pm 1.50 \\
\text { Left : } 7.29+1.20 \\
\text { OUTER: Right : } 9.68 \pm 2.18 \\
\text { Left : } 9.54+1.77\end{array}$ & $\begin{array}{l}\text { Right : } 8.49 \pm 1.43 \\
\text { Left : } 7.96+1.57\end{array}$ & $\begin{array}{l}\text { Right : } 3.87 \pm 0.83 \\
\text { Left : } 3.92+1.10\end{array}$ & --- & --- \\
\hline $\begin{array}{l}\text { Akram } \\
\text { [19][Egypt,2009] }\end{array}$ & --- & -- & $\begin{array}{l}\text { Right: } 4.48+0.9 \\
\text { Left: } 4.49+0.9\end{array}$ & --- & -- \\
\hline $\begin{array}{l}\text { Ravichandran [16] } \\
\text { [South India, 2011] }\end{array}$ & $\begin{array}{l}\text { INNER: Right: } 7.71 \pm 1.16 \\
\text { Left : } 7.49+1.33 \\
\text { OUTER: Right: } 8.1 \pm 1.58 \\
\text { Left : } 8.24+1.37\end{array}$ & $\begin{array}{l}\text { Right : } 7.89 \pm 1.29 \\
\text { Left : } 8.08+1.37\end{array}$ & $\begin{aligned} \text { Right }: & 4.7 \pm 0.98 \quad \text { Left } \\
& : 4.55+0.84\end{aligned}$ & $\begin{array}{l}\text { Right: } 14.26 \\
\text { Left: } 14.30\end{array}$ & $\begin{array}{l}\text { Right: } 17.04 \\
\text { Left: } 17.82\end{array}$ \\
\hline $\begin{array}{l}\text { Gupta[17] } \\
\text { [South India,2013] }\end{array}$ & --- & --- & --- & $\begin{array}{l}\text { Right: } 12.8 \\
\text { Left:13.8 }\end{array}$ & $\begin{array}{l}\text { Right:23.0 } \\
\text { Left:22.0 }\end{array}$ \\
\hline $\begin{array}{l}\text { Mukesh [18] } \\
\text { [India, 2014] }\end{array}$ & --- & --- & $\begin{array}{l}\text { Right: } 3.79 \pm 1.08 \\
\text { Left: } 4.05+0.86\end{array}$ & $\begin{array}{l}\text { Right: } 10.73 \pm 2.9 \\
\text { Left: } 9.72+2.56\end{array}$ & $\begin{array}{l}\text { Right:20.4+1.82 } \\
\text { Left:18.86+1.58 }\end{array}$ \\
\hline $\begin{array}{l}\text { Present study [South } \\
\text { India, 2021] }\end{array}$ & $\begin{array}{l}\text { INNER: Right: } 7.69 \pm 1.13 \\
\text { Left : } 7.52+1.24 \\
\text { OUTER: Right : } 8.21 \pm 1.24 \\
\text { Left : } 8.27+1.32\end{array}$ & $\begin{array}{l}\text { Right : } 7.78 \pm 1.21 \\
\text { Left : } 8.12+1.44\end{array}$ & $\begin{array}{l}\text { Right: } 4.76 \pm 0.91 \\
\text { Left : } 4.62+1.04\end{array}$ & $\begin{array}{l}\text { Right:12.89 } \pm 1.06 \\
\text { Left:10.74+1.12 }\end{array}$ & $\begin{array}{l}\text { Right:23.86 } \pm 1.11 \\
\text { Left:20.19+1.24 }\end{array}$ \\
\hline
\end{tabular}


Various authors have quoted the safe zone for surgical manipulations on the posterior arch of the atlas to avoid iatrogenic injury to the vertebral artery. According to Simpson et al [20], the surgical exposure of the posterior arch should not exceed $15 \mathrm{~mm}$ from the midline in adults and $10 \mathrm{~mm}$ in children. Max Franco [15] suggested that the posterior dissection of the posterior arch should be limited to a distance of $11.2 \mathrm{~mm}$ from the midline.

Stauffer ES [21] recommends a safe zone of 10 $\mathrm{mm}$ from the posterior midline. Ebraheim et al [22] noted the safe zone as $10 \mathrm{~mm}$ for males and $9 \mathrm{~mm}$ for females from the posterior mid line. All these data belong to the Western literature. Our results coincide with the results which were observed by Max Franco [15]. Ravichandran [16] had recommended a safe zone of $11.26 \mathrm{~mm}$ from the midline in the posterior approach for the atlas vertebra. However, the standard textbooks on posterior exposure suggest a safe distance of $15 \mathrm{~mm}$ from the midline $[23,24]$. The present study the mean distance between the midline and the edge of the VAG as observed in our study would be $11.82 \mathrm{~mm}$, which could be taken as the safe zone from the midline.

\section{CONCLUSION}

This study which was done on 50 atlas vertebra provides morphological data about the vertebral artery groove. The knowledge of the safe zone for surgical manipulations from the posterior midline in the local population is mandatory for the surgeons who operate in this area. The present study recommends a safe zone of $11.82 \mathrm{~mm}$ from the midline in the posterior approach for instrumentations in atlas vertebra to minimize vertebral artery injuries. Since the mean length of the vertebral artery groove from the midline is statistically lesser on the left than the right, care must be taken while performing instrumentations on the left.

This study aims at helping and assisting the spine surgeons in gauging the depth of dissection in posterior spinal approaches with prior outlining of the medial and lateral borders of vertebral artery groove to avoid untoward vascular complications.

ORCID

https://orcid.org/0000-0002-8991-7805

\section{Conflicts of Interests: None}

\section{REFERENCES}

[1]. Standring S, Churchill Livingstone; Gray's Anatomy: The Anatomical basis of Clinical Practice 41st edition, Elsevier 2016. p. 458.

[2]. C.W. Peng et al. Vertebral artery injury in cervical spine surgery: anatomical considerations, management, and preventive measures .The Spine Journal 2009;9:70-76.

[3]. Daentzer D, Deinsberger W, Boker D et al. Vertebral artery complications in anterior approaches to the cervical spine: report of two cases and review of literature. Surg Neurol 2003;59:300-9.

[4]. Smith M, Emery S, Dudley A et al. Vertebral artery injury during anterior decompression of the cervical spine: a retrospective review of ten patients. J Bone Joint Surg 1993;75(B): 410-5.

[5]. Gluf W, Schmidt M, Apfelbaum R. Atlantoaxial transarticular screwfixation: a review of surgical indications, fusion rate, complications, and lessons learned in 191 adult patients. J Neurosurg Spine 2005;2:155-63.

[6]. Mendez J, Gonzales-Llanos F. Endovascular treatment of a vertebral artery pseudoaneurysm following posterior C1-C2 transarticular screw fixation. Cardiovasc Intervent Radiol 2005;28:107-9.

[7]. Prabhu V, France J, Voelker J et al. Vertebral artery pseudoaneurysm complicating posterior C1-2 transarticular screw fixation: case report. Surg Neurol 2001;55:29-34.

[8]. Cosgrove Gr, Theron J. Vertebral arteriovenous fistula following anterior cervical spine surgery: report of two cases. J Neurosurg 1987;66:297-9.

[9]. Shintani A, Zervas N. Consequence of ligation of the vertebral artery. J Neurosurg 1972;36:447-50.

[10]. Wright Nm, Lauryssen C. Vertebral artery injury in C1-2 transarticular screw fixation: results of a survey of the AANS/CNS section on disorders of the spine and peripheral nerves. J Neurosurg 1998;88:634-40.

[11]. Madawi Aa, Case Ath, Solanki GA, et al. Radiological and anatomical evaluation of the atlantoaxial transarticular screw fixation technique. J Neurosurg 1997;86:961-8.

[12]. Neo M, Sakamoto T, Fujibayashi S, et al. A safe trajectory for atlantoaxial transarticular screw fixation achieved using an aiming device. Spine 2005;30:E236-42.

[13]. D.J. Lunardini et al. Vertebral artery injuries in cervical spine surgery. The Spine Journal 2014;14:1520-1525.

[14]. Eskander Ms, Drew Jm, Aubin ME, et al. Vertebral artery anatomy: a review of two hundred fifty magnetic resonance imaging scans. Spine 2010;35:2035-40. 
Suganya Saminathan. Morphometric Analysis of Vertebral Artery Groove in Human Atlas Vertebra in South Indian Population.

[15]. Max Franco De Carvalho, Roberta Teixeira Rocha et al. Vertebral artery groove anatomy. Acta Ortopedica Brasileira 2009;17(1):50-54.

[16]. Ravichandran D, Vertebral Artery Groove in the Atlas and Its Clinical Significance. Journal of Clinical and Diagnostic Research. 2011 June;5(3):542-545.

[17]. Gupta T, Quantitative anatomy of vertebral artery groove on the posterior arch of atlas in relation to spinal surgical procedures. Surg Radiol Anat May2008;30(3);239-42.

[18]. Akram M Awadhalla, Morphometric analysis of the vertebral artery groove of the first cervical vertebra (atlas); PanArab Journal of Neurosurgery ;April 2009;13;67-71.

[19]. Mukesh S, Distance between Midline and Vertebral Artery Groove of Atlas - A Real Aid to the Neurosurgeon. Journal of Surgical Academia 2014;4(1):26-29.

[20]. Simpson Jm, Ebraheim Na, Jackson WT et al. Internal fixation of the thoracic and lumbar spine by using Roy-Camille plates. Orthopedics 1993;16:663-72.
[21]. Stauffer ES. Posterior atlanto-axial arhtrodesis: the Gallie and Brooks techniques and their modifications. Tech Orthop. 1994;9:43-8.

[22]. Ebraheim Na, Xu R, Ahmad M. The quantitative anatomy of the vertebral artery groove of the atlas and its relationship to the posterior atlantoaxial approach. Spine. 1998;23:320-3.

[23]. Maxim R. Leventhal. Campbell's Operative Orthopaedics In: Spinal Anatomy and Surgical Approach. 9th edn; Vol. 3. Mosby, St. Louis; 1998;2681-270.

[24]. Pandey, Suniti \& Singh, Rahul. Surgical anatomy of vertebral artery groove. Journal of the Anatomical Society of India. 2018;67:S49.

How to cite this article:

Suganya Saminathan. Morphometric Analysis of Vertebral Artery

Groove in Human Atlas Vertebra in South Indian Population. Int J

Anat Res 2022;10(1):8238-8243. DOI: 10.16965/ijar.2021.194 